\title{
An Exploration of Regional Labor Productivity Patterns of Manufacturing SMEs in Mexico
}

\author{
Miguel Flores ${ }^{1}$, Roldán Andrés-Rosales ${ }^{2, *}$ and Amado Villarreal ${ }^{1}$ \\ ${ }^{1}$ Escuela de Gobierno y Transformacion Publica, ITESM, Mexico \\ ${ }^{2}$ Conacyt Research Fellow-Centro Geo, Centro de Investigación en Geografía y Geomática, Mexico
}

\begin{abstract}
The goal of this paper is to characterize the small and medium-sized enterprises (SMEs) in Mexico by analyzing regional and industrial labor productivity growth differences in the manufacturing sector during the period 2004-2014. The results suggest that labor productivity differs according to the size of the establishment. While microenterprises and small establishments exhibit a moderate increase, medium- and large-sized establishments experience the largest increase during such period. The empirical analysis indicates the existence of absolute and conditional convergence in productivity growth for the SMEs. Industry differences across locations seem to be an important factor although regional differences account for the greater variation in productivity growth.
\end{abstract}

Keywords: Convergence, SMEs, economic growth.

\section{INTRODUCTION}

Small and medium-sized enterprises are a fundamental driver of employment and entrepreneurship growth, especially in regions where they tend to be agglomerated (OECD, 2010). However, Mexico is characterized by notable regional differences in levels of economic and social development. In this context, the benefits of increasing integration into the global economy have been unevenly felt, as some regions are better positioned for access to international markets. Regional disparities in economic development are reflected in the geographical distribution of SMEs categories as well, which also contributes to differences in productivity.

In the case of Mexico, several studies have identified that microenterprises suffer from low productivity (Bolio et al., 2014). This low productivity is due in part to the large number of companies that operate outside the formal sector. Informal businesses lack access to credit and try to be invisible rather than grow, but in this case we are focused on the formal sector, which are legally registered and do not take account the informal sector for our analysis. Hanson (2010) claims that poorly functioning credit markets, along with perverse incentives to informality, have favored the survival of small and unproductive enterprises. It takes great effort to help these companies modernize, enter the formal sector, and increase their productivity and contribution to value added (OECD, 2013).

\footnotetext{
*Address correspondence to this author at the Conacyt Research FellowCentro Geo, Centro de Investigación en Geografía y Geomática, Mexico; Tel: (55) 2615-2224; E-mail: randres@centrogeo.org.mx JEL: C5, O40, O47.
}

In what appears to be a highly productive modern economy there exists allow productivity, more traditional economy; these two components of the Mexican economy are moving in opposite directions. While the modern sector flourishes, competes globally, and raises productivity rapidly, productivity is plunging in traditional Mexico (the one with very small, often informal enterprises) (Bolio et al., 2014). Traditional Mexico is creating more jobs than modern Mexico, and is therefore shifting labor from high-productivity work to low-productivity work. The challenge here is that largesized firms do not have strong linkages with the SMEs coupled with the slow growth of the country. In other words, modern-sector growth and productivity are increasingly eclipsed by the weakness of the traditional sector. While large modern corporations raised productivity by $5.8 \%$ per year from 1999 to 2009 and mid-sized companies raised productivity by $1.0 \%$ per year, the productivity of traditional enterprises fell by a staggering $6.5 \%$ a year (Bolio et al., 2014; pp. 6). The impact of that is magnified because the number of workers in traditional enterprises is growing: in 1999, $39 \%$ of all workers were employed in low-productivity traditional enterprises; by 2009, that proportion rose to 42\% (Bolio et al., 2014:19).

The critical role played by SMEs in the creation of economic development, employment opportunities, and development of entrepreneurial capacity has increased in recent years. In fact, a federal program launched in 2012 called the National Council for the Competitiveness of Micro, Small and Medium Entrepresises (Consejo Nacional para la Competitividad de la Micro, Pequeña y Mediana Empresa or CNCMIPYME) has a primary objective to promote and follow up on all diverse nationwide 
initiatives aimed to increase the productivity of SMEs and to improve the structural features of the sector (Secretaria de Economia 2012). One must note that the classification of SMEs in Mexico does include three strata, according to the number of employees in each establishment: Micro (0-10 employees), Small (11-50 employees), and Medium (51-250 employees). SMEs for the purposes of the present study include the groups of micro, small, and medium enterprises (INEGI, 2011).

In a parallel effort to increase labor productivity and improve social and economic conditions in depressed regions of Mexico, the Federal Government has initiated the implementation of the Regional Program for the Development of Southeast (in Spanish Programa Regional de Desarrollo del Sur-Sureste, 2014-2018). The main characteristic of this program is the formation of a special economic zone that covers the states of Campeche, Puebla, Quintana Roo, Tabasco, Guerrero, Oaxaca, Chiapas, Veracruz, and Yucatan (see Appendix A). This program attempts to facilitate the coordination of federal, state and local entities in order to promote high-impact infrastructure and urban development projects to facilitate regional connectivity with the rest of Mexico and create the institutional environment needed for long-term regional development planning. Encouraging entrepreneurship and productivity and technological upgrading of companies - with a focus on micro, small and medium enterprises - is one of the program's overall goals (SEDATU 2014, pp. 94).

This paper is intended to contribute to the discussion of the importance of SMEs in local economic development. The main interest of this study is to characterize the presence of SMEs in Mexico by analyzing regional labor productivity growth differences. In doing this, the empirical analysis relies on the estimation of convergence models of SMEs in the manufacturing sector; by using the most recent Economic Census, it is possible to perform the analysis for the period 2004-2014. The analysis focuses on the manufacturing sector, given that traded industries offer more potential for exporting opportunities, which depend on the productivity and competitiveness of this industry. According to the 2014 Economic Census, manufacturing SMEs make up $46 \%$ of the sector's total employment. The selection of the industrial sector is also justified by its ability to absorb rapidly technological progress and by the possibility of the spillover effects that this sector may exert on other sectors (Hulten, 2001). In this sense, an analysis focusing on regional productivity of manufacturing SMEs is key to the design of development policies in current productive systems. Hence, the present analysis brings new insight to the discussion of how to increase regional productivity levels across the country.

\subsection{The Role of SMEs in Mexico}

Mexico's economic approach to development has focused mainly on the expansion of economic growth, employment creation, reduction of inflation, the allocation of more resources to social expenditures, and, finally, to strengthen the economy to prevent a financial catastrophe. Mexico restructured its financial policies together with reactivation of the more vibrant production sector and employment opportunities. These were the grounds upon which the country laid its economic aims. The approach promoted private business initiatives, which were initially under the government's control. In addition, the country also fostered provision of credit to small investments that benefitted large, medium and small enterprises. Despite the fact that these benefits have not trickled down to local SMEs as expected, much progress has been noted in terms of the creation of awareness and the enlightenment of aspiring and potential entrepreneurs. Fong (2009) argues that the government has not come up with an elaborate policy that boosts competition to establish new firms and integrate innovative SME's into regional and local marketplaces. Currently, SMEs lack competitive strategies that would help them increase productivity.

These factors promoted the creation of an environment conducive to the creation of microenterprises (i.e., establishments with 10 or fewer employees). Additionally, the formation of public programs with the aim of promoting productivity of microenterprises further helped businesses across the country. These programs were initiated in various areas, including financial support, labor policy, tourism, science and technology, agriculture, social development, fisheries and education. The programs have helped further development of SMEs in Mexico with the initiation of regulations and policies that aim to stimulate regional development and competition among the enterprises. The economic factors have supported great progress for more enterprises, helping them take on a more international look and consider engaging in exports. The adoption of these policies has used several means to facilitate SMEs progress; credit and loans, trade agreements, and financial support have greatly promoted the creation of more SMEs in Mexico. 
One of the distinctive features of the Mexican economy is that SMEs make quite a small contribution to value-added. They represent only $53.6 \%$ of the total value added in Mexico, a percentage that is below the corresponding figure in most other OECD economies where the average added value of SMEs is about $60 \%$ (OECD 2013, pp. 34). Nonetheless, SMEs are accountable for roughly $75 \%$ of total employment, suggesting a shortfall in productivity. To a large extent, this reflects the relative weight of microenterprises (establishments with 10 or fewer employees) in the SME sector in Mexico, but also the relatively low productivity level of these microenterprises. While in some developed countries (such as the US or UK) it represents close to $50 \%$, in others, such as Greece or Italy, SMEs account for more than $80 \%$ of total employment.

One must also note that before the global financial crisis of 2009, Mexico was already experiencing a drop in economic activity which, according to data from the Economic Census, was reflected in an average annual reduction of $0.3 \%$ in manufacturing employment between 2003 and 2008. As a consequence, employment in the manufacturing industry declined by $1.3 \%$ over that period. Figures $\mathbf{1}$ and $\mathbf{2}$ show the annual growth rate of employment and value added, respectively, for all industries and for the manufacturing

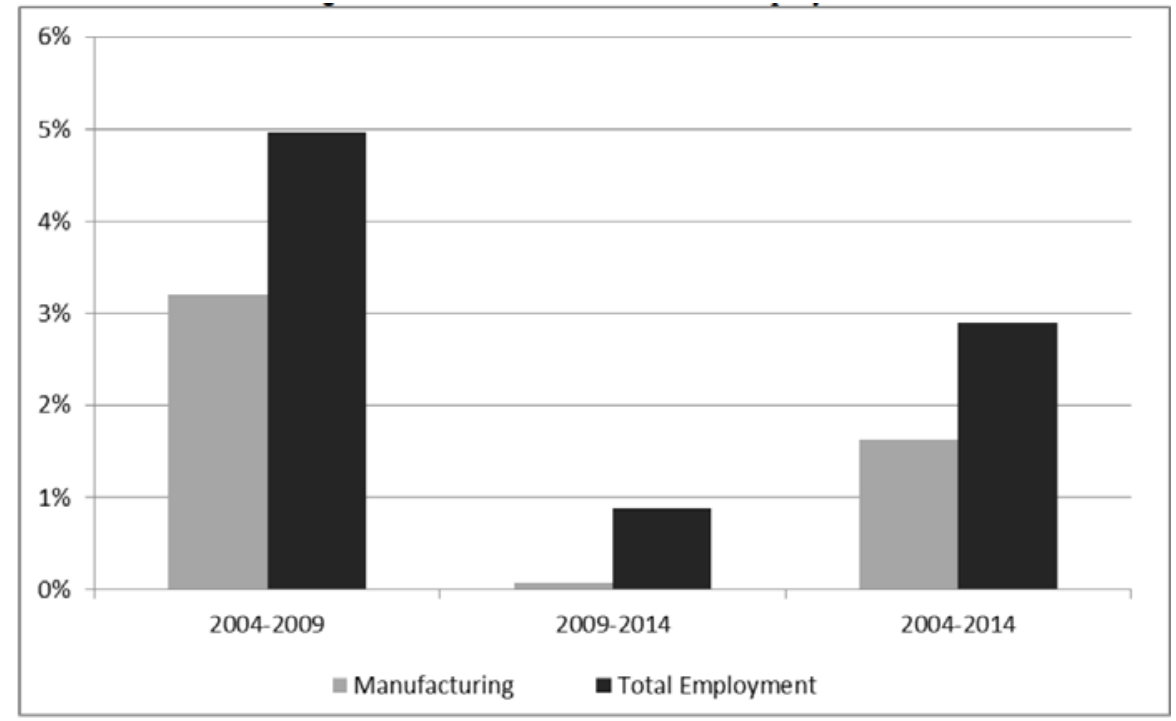

Figure 1: Annual Growth Rate of Employment.

Source: Own elaboration with data from the Economic Census, years 2004, 2009, and 2014.

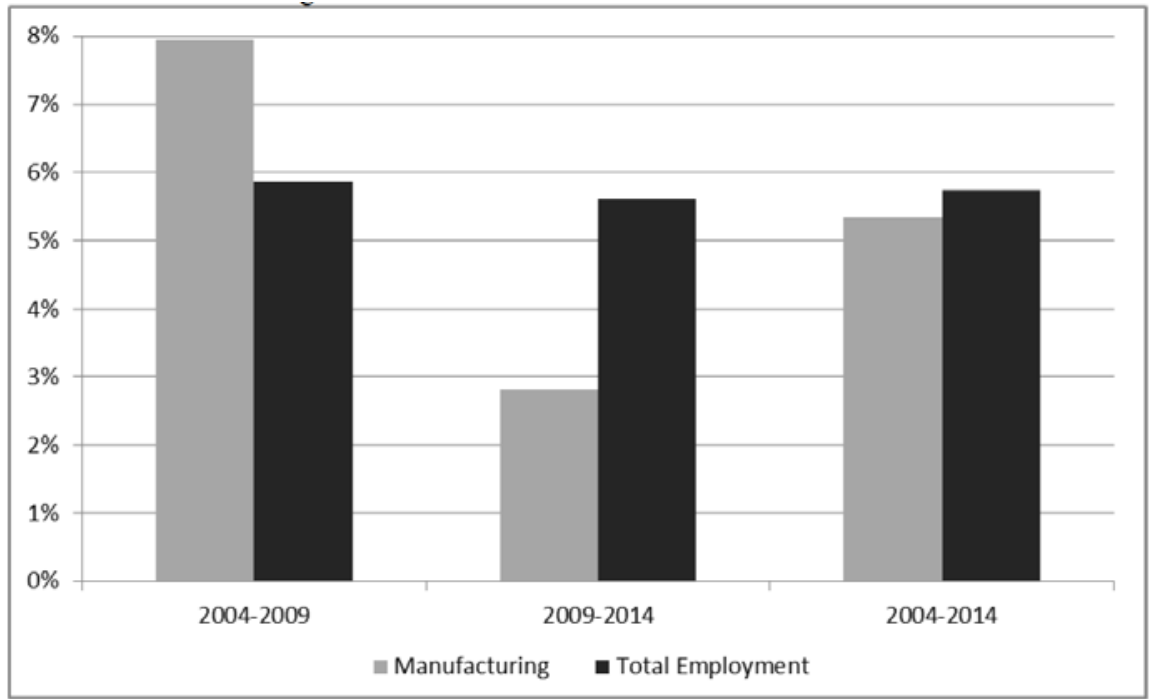

Figure 2: Annual Growth Rate of Value Added.

Source: Own elaboration with data from the Economic Census, years 2004, 2009, and 2014. 


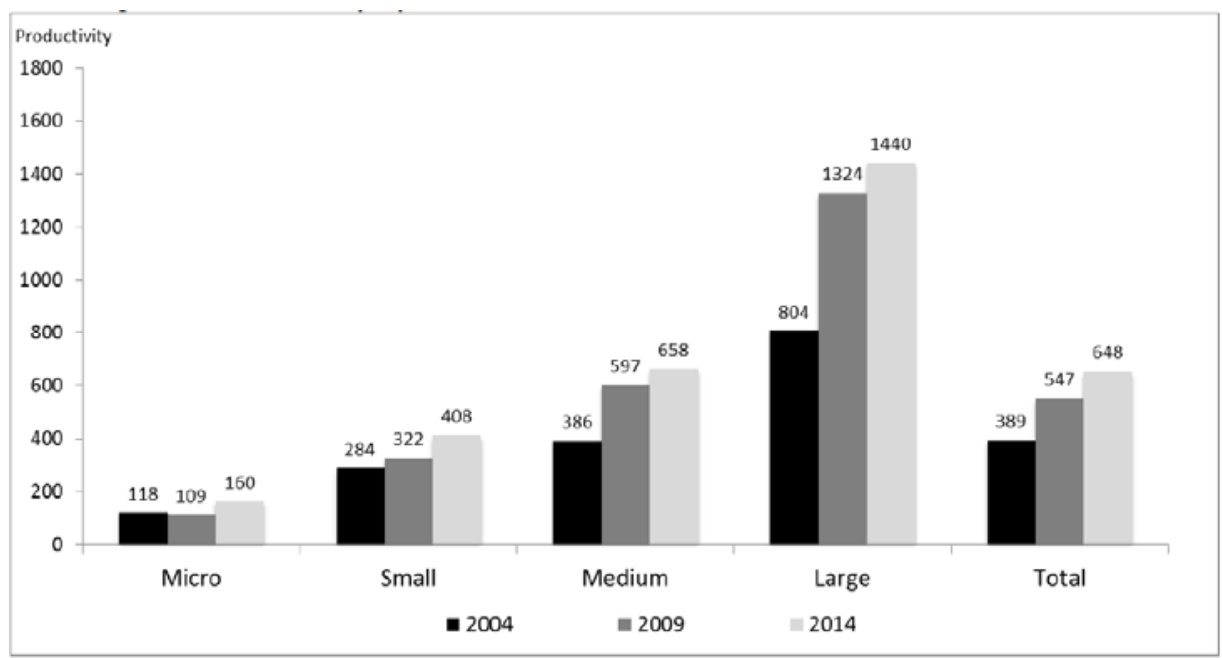

Figure 3: Productivity by establishment size in Mexico, 2004, 2008, and 2014.

Source: Own elaboration with data from the Economic Census, years 2004, 2009, and 2014.

sector exclusively, contrasting three different periods: 2004-2009, 2009-2014 and 2004-2014 ${ }^{1}$. As noted, the average growth rate of employment in the SMEs group for the whole period is lower than for that registered during the first five years of the period. The observed trend was even less optimistic for microenterprises, in that their growth for the period 2009-2014 did not even reach $1 \%$, neither in total nor in the manufacturing sector. Manufacturing employment showed a lower annual growth rate compared to total value-added growth. While the national employment growth rate was about $2.9 \%$, on average, the SMEs experienced a growth rate of $1.6 \%$. An interesting pattern is observed when comparing value added in total and manufacturing growth rates for the first two periods. While manufacturing showed a higher rate for the period 2004-2009, a significant reduction in the growth rate is observed during 2009-2014. As seen in this figure, the downtown of economic activity stemming from the global financial crisis in the late 2000s had important consequences for the Mexican economy in terms of both employment and production levels.

From the above information, it is possible to obtain a basic measure of labor productivity, such as the ratio of value added per worker (in the same way that Dollar and Wolf calculated the labor productivity in 1988). This is displayed in Figure 3, which shows labor productivity trends in establishments according to their size for the years for which information is available. Only microenterprises failed to show any growth in productivity in 2004 or 2009 but had a small increase in

'Data from Economic Census for the years 2004, 2009 and 2014.
2004-2014. While small establishments exhibited a moderate increase, medium- and large-sized establishments experienced the largest increase in productivity, actually the medium enterprises doubling their labor productivity in 2014 compared to 2004, although it showed the highest growth from 2004 to 2009 and lower in the last period. In the large size enterprises the highest productivity is observed. It is interesting to note that the micro enterprises increased their productivity in the second quarter as compared to the first, contrary to other size-type companies where productivity growth is seen more in the first period. One explanation may involve the trade liberalization process where large companies and SMEs to the US market are becoming somewhat integrated, but not micro enterprises. Nonetheless, learning and recession have caused micro dynamism better than large companies in the last period due in part that micro companies are more focused on the domestic market and large companies to the international market.

How does the above analysis translate to differences in the regional labor productivity of SMEs? The analysis so far has established that lagging regions in the country tend to have a higher concentration of SMEs. This might also suggest the existence of spatial variations in the performance of SMEs in terms of productivity. This is corroborated in Figure 4, as the patterns of productivity per worker that emerge in 2009 exhibit a core-periphery orientation, in which the performance tends to be lower in southern states. Specifically, the neighboring states of Chiapas, Oaxaca, Guerrero, and Michoacan, along with the central state of Tlaxcala, are the five states with the lowest productivity in Mexico. In terms of the top five 


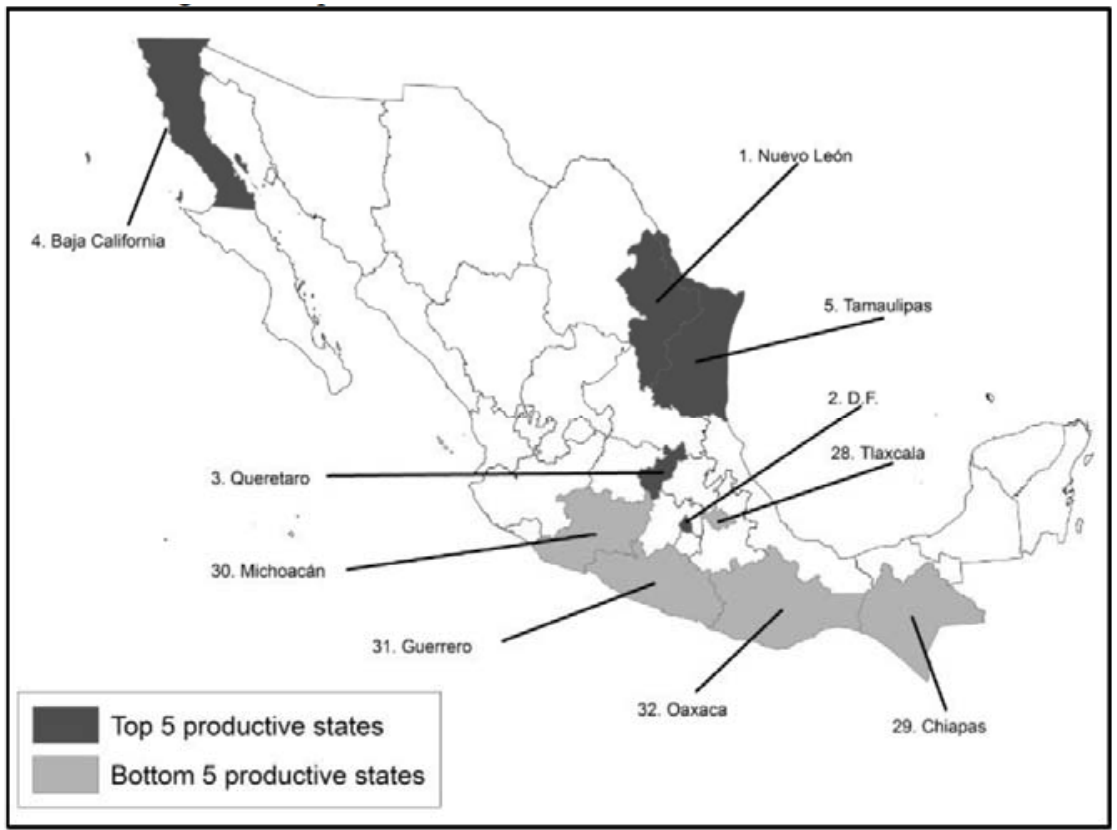

Figure 4: Top and Bottom 5 Five Productive States in SMEs.

Source: Own elaboration with data from the Economic Census 2009.

states with the highest productivity, two are central states (Distrito Federal and Queretaro) and the other three are northern states that border the U.S. (Tamaulipas, Nuevo Leon, and Baja California).

More marked regional differences arise when looking at the average productivity for the whole period, 2004-2014. Figure 5 shows the distribution of labor productivity by quintiles in Mexican states from which is observed that most of the northern states rank in the highest quintile of the distribution. Note also a distinctive pattern of those states with higher productivity levels that are located near Mexico City, including the states of Queretaro and San Luis Potosi. Most of the southern states are found in the bottom quintile for productivity in this period.

It is important to mention that over the past three decades, Mexico's industrial development has occurred within a process of trade liberalization. This

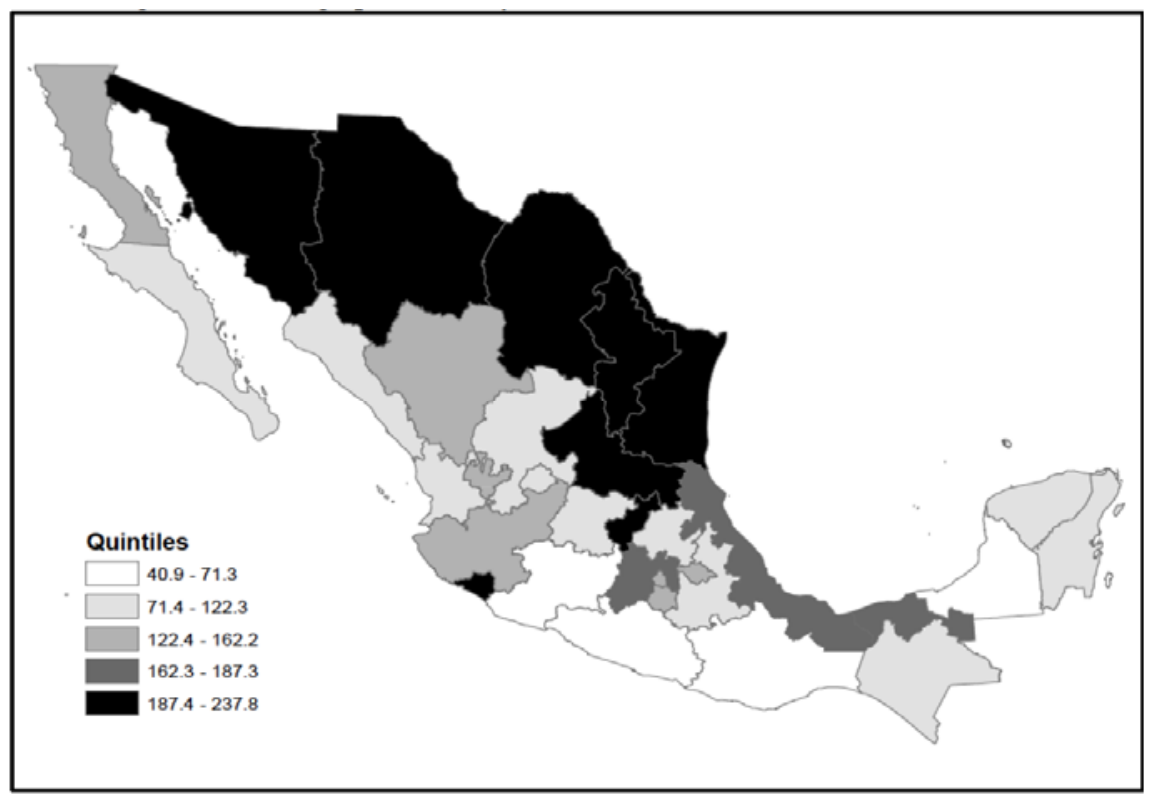

Figure 5: Average productivity of SMEs in Mexican States, 2004-2014.

Source: Own elaboration with data from the Economic Census, years 2004, 2009, and 2014. 


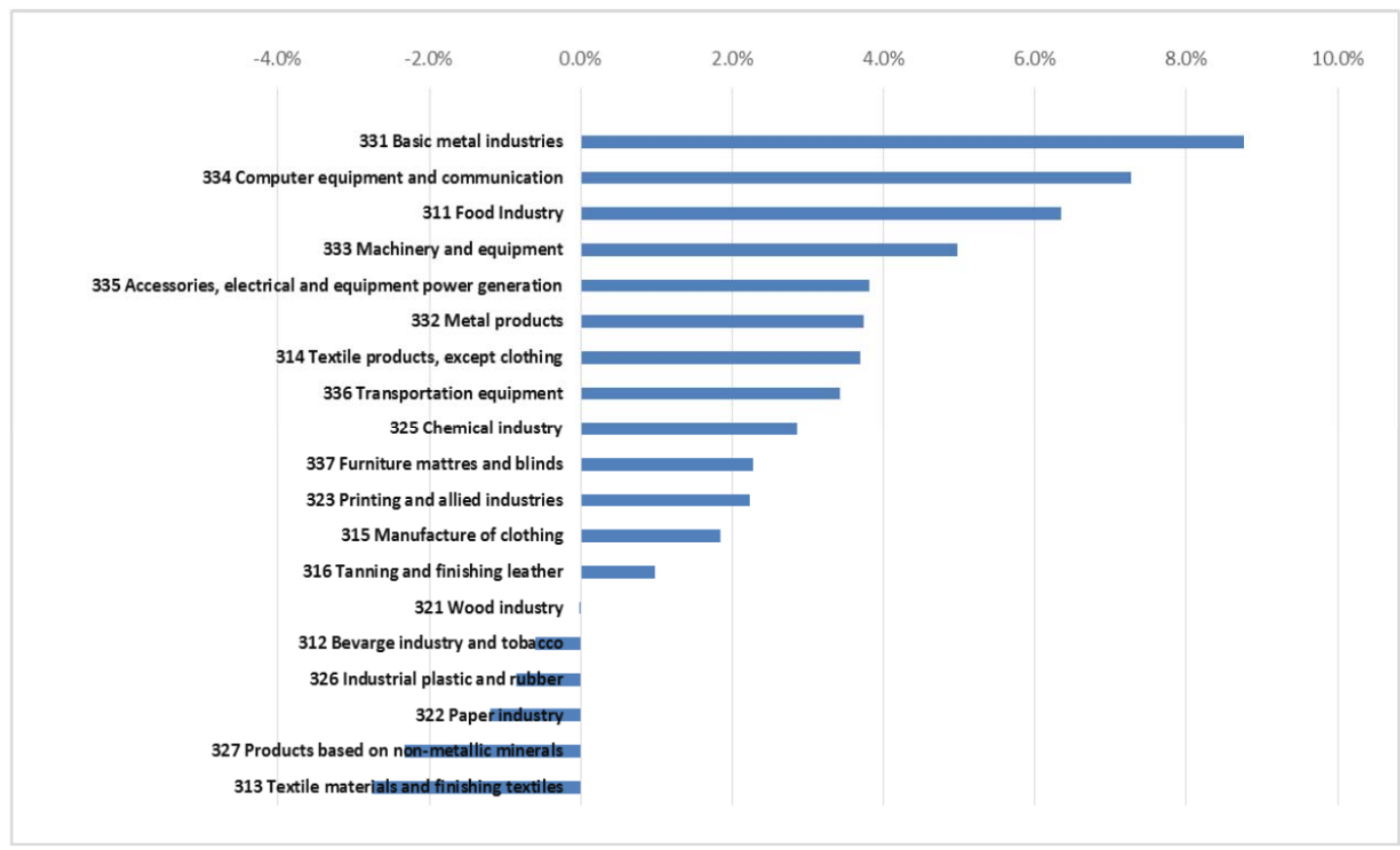

Figure 6: Annual Productivity Growth of SMEs by Industry in Manufacturing, 2004-2014.

Source: Own elaboration with data from the Economic Census, years 2004, 2009, and 2014.

process began in the late 1980s, culminating with the implementation of the North American Free Trade Agreement (NAFTA) in 1994, which aimed to gradually eliminate barriers to trade and financial flows among the member countries (Canada, Mexico, and the United States). As a result of economic liberalization, the internal structure of the Mexican economy was altered in terms of its composition, size, and the geographical location of industrial concentration. These changes have directly, and to some extent, differentially, influenced regional socioeconomic development and production capabilities as a result of the allocation of important input factors - namely, labor, capital, and land. It follows that the geographical outcomes for economic activity are due to the effects of NAFTA, and that the occurrence of regions of industrial concentration could also be associated with industrial labor productivity differences.

In this sense, notable differences are also found when exploring labor productivity growth by industry. Figure 6 shows the growth in labor productivity for all manufacturing industries at the NAICS 3-digit level over the 10- year period considered here. Only three industries show a growth rate higher than $5 \%$ : basic metal industries (NAICS 331), computer equipment and communication (NAICS 334), and the food industry (NAICS 311). Six out of the 19 industries exhibit a decrease in productivity; textile materials and finishing textiles (313) had the greatest reduction in productivity growth during this time. The remaining 13 manufacturing industries showed a moderate increase in productivity levels.

The goal of this section was to provide a brief overview of labor productivity differences in Mexico's manufacturing SMEs. As discussed, the analysis so far has discussed differences not only across Mexican regions, but differences related to the manufacturing industry considered. These two components should be considered when exploring factors associated with these productivity differences in SMEs. The next section is devoted to such purposes. Specifically, the focus will be on modelling a productivity growth economic convergence framework while explicitly addressing regional and industrial differences.

Following to Dollar and Wolff (1988), let $v^{h}$ be an $n$ $X 1$ vector of fixed factor supplies for region $h$. Using a DGP or aggregate value added for region $h$ can be expressed as the sum of factor earnings: $y^{h}=w^{\prime} v^{h}$, where $\mathrm{w}$ is the factor price equalization and is the same for all regions. If we let the first factor in the vector vh be aggregate labor supply, $\mathrm{L}^{\mathrm{h}}$, the labor productivity can be expressed as $y^{h}=L^{h}=w_{L}+\sum_{i=2}\left(w_{i} v_{i}^{h} / L^{h}\right)$. Aggregate labor productivity is a weighted average of labor productivity in individual manufacturing industries, $\frac{y^{h}}{L^{h}}=\sum_{j}\left(\lambda_{j}^{h} y_{j}^{h} / L_{j}^{h}\right)$, where the weights are employment shares $\left(\lambda_{j}^{h}=L_{j}^{h} / L^{h}\right)$. In short, "the model predicts that 
high labor productivity at the aggregate level must result from having an employment mix shifted toward high-productivity industries. Industries with high value added per workhour are those that employ much human capital, physical capital, or other non-labor resources per workhour" (Dollar and Wolff, 1988, pp. 550). Hence, we understand labor productivity as real output per labor hour, and growth in labor productivity is measured as the change in this ratio over time (Sprague, 2014). Its importance as defined by Munnell (1990:3), "productivity growth is the major determinant of the future standard of living.

\section{METHODS: CONVERGENCE ON SMES PRODUCTIVITY}

From the neoclassical growth framework discussed by Solow (1956), it is possible to model economic growth under the assumptions of constant returns to scale in labor and capital with decreasing marginal returns in capital. This basic specification allows for a framing of regional economic growth in which each economy converges to its own steady state, so that the speed of convergence is inversely related to the distance from the steady state (Barro and Sala-i-Martin 2004). Under the hypothesis that poor economies tend to grow faster than rich ones, without conditions on any other characteristics and assuming that all economies exhibit the same steady-state positions, the log version of an absolute convergence equation can be estimated through the following expression:

$$
\begin{aligned}
\frac{1}{T} \operatorname{Ln}\left(\frac{Y_{s, i, T}}{Y_{s, i, 0}}\right)_{i}= & \alpha+\beta \ln \left(Y_{s, i, 0}\right)_{s i}+D_{s}+D_{i}+\varepsilon_{s i} \\
& \varepsilon_{s i} \approx i . i . d\left(0, \sigma^{2} \varepsilon\right)
\end{aligned}
$$

Convergence in labor productivity at the industry level (as in the context of this study), would indicate that if an industry is further away from its steady state level, it experiences faster productivity growth. Note that $Y_{s, i, 0}$ and $Y_{s, i, T}$ denote productivity at the beginning and end of the period, $s$ is an index for the crosssectional dimension (spatial units) (in this case, States), $i$ corresponds to the index for the industry, and $T$ denotes the length of the time interval under consideration $(T=10)$. Labor productivity in the manufacturing sector is then defined as $Y_{s, i, T}=\ln \left(v a_{s i} / \mathrm{em}\right)$ where va is the value added, em is the total working population in the same sector. The equation also controls for state-industry specific conditions with dummy variables $D_{s}$ and $D_{i}$, and finally, $\quad \varepsilon_{s i}$ is an independently and identically distributed error term for state $s$ and industry $i$.

When modeling absolute convergence, equation (1) includes the initial level of productivity as an explanatory variable. This variable is usually considered as an indicator of convergence; a negative coefficient suggests a 'catch-up' process. In the context of this analysis, it is anticipated that lagging regions will experience faster productivity growth rates than leading regions, which leads to the eventual convergence of productivity growth across regions where all regions grow at the same rate. For further references on labor productivity modeling, see Munnell (1990), Cravo et al., 2012; and Fazio \& Piacentino (2010).

From the estimated $\beta$ coefficient it is possible to approximate the "speed" and, consequently, the halflife convergence. This is the number of years for the productivity level to move halfway to its initial level $Y_{s, i, 0}$. Following Barro \& Sala-i-Martin (2003, pp. 58), this is approximated by the following expression:

$T=\ln (2) / \beta$

The Economic Census for the years 2004 and 2014 provides data on value added and total employment for 21 manufacturing industries at the 3-digit level for each of the 32 Mexican States ${ }^{2}$. Unfortunately, value added information for some industries is not available for some of these years, which creates unbalanced panel data. The descriptive statistics of the variables and the source of information are shown in Appendix B.

In the case of heterogeneity across state economies, states endowed with differences in capital stock (for example) and, consequently, with different stationary steady states, leads to the estimation of conditional convergence models. In this case, SMEs' productivity growth is assumed to be a function of some explanatory variables $X$, as shown in the following expression:

$$
\begin{aligned}
\frac{1}{T} \operatorname{Ln}\left(\frac{Y_{s, T}}{Y_{s, 0}}\right)_{i} & =\alpha+\beta \ln \left(Y_{0}\right)_{i}+\gamma X_{0}+\varepsilon_{i} \\
\varepsilon_{i} & \approx i . i . d\left(0, \sigma^{2} \varepsilon\right)
\end{aligned}
$$

where $X_{0}$ denotes an $(1, \mathrm{~K})$ row vector of observations of the independent variables, and $\gamma$ the corresponding vector of unknown parameters to be estimated. Noteworthy is the fact that because firm-level information was not available at the time of this study, and given that the explanatory variables do not show variation within each industry at a given location, the

${ }^{2}$ Desegregated information by establishment size and at state level using the SCIAN for the year 1999 was not available at the time of the analysis which limits the period of study as specified. 
estimation of equation (3) does not include industry fixed effects. As discussed above, the analysis considers a time frame of 10 years, from 2004 to 2014 . Productivity growth is also calculated for two subperiods, 2004-2009, and 2009-2014 with the objective of identifying a possible effect resulting from the 2008 global financial crisis, the effects of which were felt most strongly in 2009 in Mexico. The conditional regressions are then estimated from a panel of 64 observations. Hence, the relevant unit of analysis corresponds to the 32 Mexican states, and the selection of the variables includes several variables commonly identified in the literature that may be related to regional productivity differences as well as data availability.

For example, the average level of education is considered to be a major determinant of labor productivity because it is a measure of human capital (Moretti, 2013). This implies that as workers become better trained or experienced, their productivity increases. In this context, "cities with a well-educated labor force and strong innovation sector grow, add good jobs and attract even more skilled workers" (Moretti, 2013:14). They also generate more entrepreneurial activity in their regions, which is more difficult in regions with low education levels. This refers to the absorptive capacity of the region to assimilate information and to grasp and solve problems or, put differently, the learning ability of the region. The scope and quality of education plays a crucial role in the development of this ability (Sleuwaegen and Boiardi, 2014) and in the creation of innovative new ventures (Bania et al., 1993). As German-Soto and Gutierrez (2013:2) argue, "the essence of any modern economy relies on its ability to increase the application of knowledge, which makes us think about innovation in terms of knowledge used to create new knowledge." Furthermore, knowledge created in universities and other institutions of higher education is essential for the development of the required skills and expertise, and allows companies to gain access to specialized human resources (Sleuwaegen \& Boiardi, 2014).

Another variable included is the unemployment rate as a proxy for regional informality conditions. This is, in the absence of an informal labor market, represents people who are unable to access the labor market (formal) and would be either openly unemployed or out of the labor force, with no labor income (Jo Bane \& Zenteno 2009: 45). Growth in informal work activities or "informality" decreases the productivity of the regions and the companies that are part of the region. Also, people of working age are affected by the poor dynamism of the labor market, making it impossible for them to be involved in productive activities. A negative relationship between informality (as proxied by unemployment) and productivity is anticipated.

Two variables - population density, and the percentage of a population living in rural localities that respectively measure agglomeration economies and rurality conditions, are also included. Population density and a region's urbanization level are factors that could influence productivity. As a region becomes more "urbanized," it implies that there is a higher concentration of economic activities and agglomeration economies which could, at the same time, be associated with higher labor productivity. Additionally, cities work as an open system to attract talented people from various backgrounds and stimulate their creative capacities (Lee et al, 2004). It is difficult to see this phenomenon in rural areas. Rural areas, due to their characteristics, might not share the positive externalities of urban centers, leading to stagnation in productivity, or nonsignificant changes in productivity over time.

According Lee et al. (2013) and Griliches (1990), the number of patents registered offers multiple desirable attributes as a preferred proxy for the output of regional knowledge production. A greater number of patents could be associated with higher levels of innovation. This is expected to be positively associated to productivity. The analysis then considers the number of patents per capita in each of the states, and a positive and significant coefficient of this variable would be informative regarding the extent to which local innovation activities enhance productivity.

Among the independent variables, we also incorporated the insecurity level. If crime causes businesses to leave a state, the state will experience a negative growth rate in capital per person (Pan et al., 2012), causing a decrease in productivity. But if companies decide to stay in the region, an increase in crime will negatively impact labor productivity, since the cost of security measures adopted by enterprises will increase. In addition, if qualified people migrate to safer regions, the productivity of the region will be negatively affected, as only the less-experienced and lessqualified people will stay. For these reasons, homicide rates per capita were also included as an explanatory variable. 


\section{RESULTS}

Table 1 presents the results from the absolute convergence model, where each specification may include state effects, industry-fixed effects, or both. All -coefficients for the initial levels of productivity are negative, suggesting evidence of convergence in SMEs labor productivity. The fit of the absolute convergence model appears to have the greatest explanatory power when controlling for specific industry and regional fixed effects, as the adjusted R-squared is almost double of that of the model that only controls for state-fixed effects. When both state and industry effects are included, the adjusted R-squared increases to 0.38. As noted above, the fixed effects control for 21 manufacturing industries at the 3-digit level SCIAN code. These findings suggest that most of the variation in productivity growth could be attributed to industry rather than location-specific factors. This table also displays the corresponding estimate of the average convergence life. The results suggest that the number of years to cover half the distance of the logarithms of productivity is approximately 10.9 years, once controlling for state- and industry-fixed effects.

Table 2 shows the results of regional productivity growth regressions in terms of absolute and conditional convergence versions. The results also indicate absolute and conditional convergence of productivity growth during the period of study. Note that the conditional convergence specification offers an increase in the model's explanatory power as compared to the absolute convergence model. These results indicate the importance of some regional contextual factors as important explanatory factors behind labor productivity growth. First, the estimated half-life convergences are now approximately 33 and 26 years, for the absolute and conditional models respectively. These estimates are considerably higher than the previous results in Table 1, where the regressions control for location and industry-fixed effects.

However, only a few variables - among them, average schooling years, population density and unemployment and, to a lesser extent, homicide rates showed statistical significance.

The results indicate that average schooling years are positively related to productivity growth. This corroborates theoretical expectations that, in general, higher levels of education stand in the way of increased productivity in SMEs. Deprived conditions in relation to unemployment rates are negatively associated with productivity. Although this finding might seem counterintuitive, one explanation for it is that unemployment plays a central role in increasing informality rates or crime increases in the region due to lack of formal employment opportunities. This result could be endogenous, given that productivity could be associated with greater numbers of SMEs rather than higher value added per se. Population density, the variable proxy for agglomeration economies, shows both statistical significance and the expected effect. This variable could also be relevant as a demand or supply factor for employment in the manufacturing industry which, in turn, would be positively related to productivity. Homicide rates appear to be negatively associated with productivity growth, although with marginal statistical significance. This is an important

Table 1: Absolute Convergence Results for SMEs, 2004-2014

\begin{tabular}{|c|c|c|c|c|}
\hline & Model I & Model II & Model III & Model IV \\
\hline \hline Productivity at t0 & $-0.0338^{* * *}$ & $-0.0449^{* * *}$ & $-0.0406^{* * *}$ & $(0.0037)$ \\
\hline FE States & $(0.0035)$ & $(0.0038)$ & & Yes \\
\hline FE Industry & & Yes & Yes & $0.0044^{* * *}$ \\
\hline Adjusted R2 & 0.12 & 0.17 & 0.30 & 558 \\
\hline Degrees of freedom & 609 & 578 & 589 & 17.1 \\
\hline Half-Life convergence & 20.5 & 15.43 & 611 & 611 \\
\hline $\mathrm{N}$ & 611 & 611 & & 5 \\
\hline
\end{tabular}

Standard errors are in parentheses. ${ }^{*} p<0.10,{ }^{* *} p<0.05,{ }^{* * *} p<0.01$. 
Table 2: Regional Absolute and Conditional Convergence Results for SMEs, 2004-2014

\begin{tabular}{|c|c|c|}
\hline & Absolute Model & Conditional Model \\
\hline Productivity at $\mathrm{t}_{0}$ & $\begin{array}{l}-0.021^{\star \star \star} \\
(0.0063)\end{array}$ & $\begin{array}{l}-0.026^{\star \star \star} \\
(0.0080)\end{array}$ \\
\hline Patents per capita & & $\begin{array}{c}-0.005 \\
(0.0031)\end{array}$ \\
\hline Schooling Years & & $\begin{array}{l}0.237^{\star \star} \\
(0.1117)\end{array}$ \\
\hline Unemployment & & $\begin{array}{l}-0.0364^{\star *} \\
(0.0187)\end{array}$ \\
\hline Population Density & & $\begin{array}{l}0.023^{\star \star} \\
(0.0070)\end{array}$ \\
\hline \% Rural Population & & $\begin{array}{c}0.024 \\
(0.0132)\end{array}$ \\
\hline Homicides Rates & & $\begin{array}{l}-0.011^{*} \\
(0.0109)\end{array}$ \\
\hline Dummy for the period 2009-2014 & $\begin{array}{l}0.035^{\star \star} \\
(0.0063)\end{array}$ & $\begin{array}{l}0.032^{\star \star \star} \\
(0.0067)\end{array}$ \\
\hline Constant & $\begin{array}{c}0.107^{\star \star \star} \\
(0.02855)\end{array}$ & $\begin{array}{c}-0.136 \\
(0.1081)\end{array}$ \\
\hline Adjusted R2 & 0.36 & 0.45 \\
\hline Degrees of freedom & 61 & 55 \\
\hline Half-Life convergence & 33.0 & 26.6 \\
\hline $\mathrm{N}$ & 64 & 64 \\
\hline
\end{tabular}

Standard errors are in parentheses. ${ }^{*} \mathrm{p}<0.10,{ }^{* *} \mathrm{p}<0.05,{ }^{* * *} \mathrm{p}<0.01$.

finding, given the recent period of high violence levels that occurred in some regions of the country. Note that a dummy variable was added into the regression to control for the period 2009-2014 (just after the financial economic crisis of 2009) and turned out to be positive and statistically significant, although with a relatively modest magnitude.

This section has shown some evidence of industrial and regional productivity convergence patterns of SMEs in Mexican states. In general, the results confirm the existence of absolute and conditional convergence in productivity growth during the period 2004-2014. While industry differences across locations seem to be an important factor, regional differences appear to account for the greater variation in productivity growth. Nonetheless, one should be aware of some limitations inherent in the present analysis. The main one involves the lack of firm-level data that prevent more in-depth evaluation of firm productivity. The fact that only a few explanatory variables show significance, and most importantly, because the conditional convergence models greatly contribute to the variation of productivity across location and industries, suggests that the models would benefit from the use of important firmlevel characteristics at the regional scale. A second major limitation of these models that is also related to data presently available for analysis is given the limited degrees of freedom associated with these regressions and thus the low statistical confidence associated with the results

\section{CONCLUSION}

This paper provides an overview of regional and industrial productivity differences of SMEs in Mexico. 
The analysis focused on the manufacturing sector, and the findings can be summarized as follows. First, productivity differences vary according to establishment size. Microenterprises or establishments with fewer than 10 employees, is the group with the slowest growth in productivity. While small establishments exhibit moderate productivity increases, medium- and large-sized establishments experienced the largest increase, almost doubling levels in 2014 compared to 2004. Second, regional differences are also evident, showing a considerable gap among states, particularly when southern Mexico is compared to other regions within the country. Aiming to assess regional and industry differences in productivity, the empirical analysis considered the estimation of absolute and conditional convergence models. The results point to an absolute convergence in labor productivity among Mexican states, and suggest that it would take about 11 years for lagged states to catch up half-way to the initial productivity levels of the more developed ones. The main finding of this paper is that productivity on SMEs could be improved and convergence could be faster if problems such as unemployment, insecurity were met. Since these factors adversely affect the growth of the productivity of each region and its convergence. We could anticipate that the rich regions can absorb the cost of insecurity, but not poor regions.

While the results from the conditional convergence models suggest few variables associated with labor productivity, the inability to control for firm-specific characteristics is a limitation of the present analysis as are the limited degrees of freedom and lower statistical confidence associated with model results. One relevant source of information that is currently missing is a longitudinal database from which researchers can track the life of an establishment, from birth until maturity and/or death. It must be recognized that newly available sources - such as the Demographic Analysis of Establishments (Analisis Demografia de los Establecimientos, ADE 2010) (INEGI 2013) and the National Statistical Directory of Economic Units (Directorio Estadistico Nacional de Unidades Economicas (DENUE)) - are a step forward in this direction. From the latter, a geo-referenced database for all establishments in Mexico is publicly available, allowing for the exploration of the spatial colocation patterns of firms among other uses. Further, the new 2014 Economic Census provides new information at the regional scale, which in turn will enable the extension of the present analysis to more years.
As discussed in section 3, SMEs in Mexico have a productivity gap with respect to their large-sized counterparts. Hence, it is important to implement measures to improve the economic environment and directly support these companies in order to create the conditions that contribute to their founding, growth and consolidation. Given the fact that only $6 \%$ of SMEs in Mexico actually export, programs operated by the Ministry of Economy to promote and facilitate the incorporation and marketing of SMEs within export activity and the internalization of Mexican companies would play a crucial role in developing stronger SMEs (Secretaria de Economia 2008). Additionally, SMEs may also emphasize joining existing value chains via the development of supplier mechanism strategies. For example, some areas for policy intervention include skills and human resource development, technological upgrading, certification standards, and cluster and territorial development initiatives (UNCTAD, 2010).

Other programs, such as the National Fund for the Entrepreneur (Fondo Nacional del Emprendedor), offered through the National Institute for Entrepreneurship (Instituto Nacional del Emprendedor), can also help. This is another instrument to support SMEs - especially micro-sized establishments and entrepreneurs - through financial grants for particular projects that encourage the creation, development, productivity, and competitiveness. Although this study is far from being a comprehensive diagnostic of the current situation of SMEs in Mexico, it does provide a description of current productivity trends, emphasizing the effects of geography and manufacturing industry membership on productivity patterns.

Mexico has plentiful opportunities to initiate a major economic transformation via their SMEs. Nonetheless, the success of such an initiative requires support from the country's business environment, which relies on the overall commitment of the people of Mexico and the government. Several steps can be taken to improve the productivity of SMEs to grow and stabilize their operations. The following actions can be adopted and implemented in order to set a course enhance productivity in Mexico's SMEs:

\section{Reform Regulations and Reduce Incentives to Stay Informal and Small}

Laws and social programs in Mexico are meant to protect businesses, increase employment and in general worker's welfare. However, these protections have to some extent unintentionally discouraged 
development and formalization. Levy (2007) maintains and explains why, despite most SMEs having grand development agendas; some social programs are in fact distorting key determinants of growth and productivity. He argues that Mexico is caught in a dilemma between increasing worker's welfare through various forms of social interventions, one hand, and appropriate incentives to workers and firms to seek productivity increasing jobs and investments, on the other. This calls upon Mexican business leaders to rethink and examine laws that give preference to a given category of SME initiatives. The government might also consider changing the way that informal business is done by streamlining areas such as taxation, procedures for starting an SME, and zoning. For instance, the cost needed to open and register an SME in Mexico is approximately $10 \%$ of the average per-capita income. In the United States, it is only $1.4 \%$ (Potter, et al., 2013). By addressing such irregularities, the government can set in motion the development of more formal and modern SMEs. Standardizing processes makes it even easier for SMEs to invest further in the country and grow.

A large number of SMEs are informal and operate without complying with the legal requirements of the government. This is particularly common in low-income regions such as Guerrero and Oaxaca. By addressing the operational informality of these SMEs, the government can lay solid groundwork for growth and expansion of the Mexican economy. This, too, would address the informal employment prevalent in the sector. In order to inspire more formality, the government and relevant authorities ought to boost the chances of inspections for non-compliance with regulations (Potter, et al., 2013). This enforcement could include acts such as random labor inspections at business enterprises to identify firms that operate without complying with law.

\section{Expansion of Access to Capital}

Access to capital is vital to the growth and development of SMEs. Measures initiated by the government, such as protection of creditors and open procedures for recovering loans and collateral from borrowers, are not yet bearing fruits as expected, although some economic changes can be noted within small firms. While large corporations can access funds due to the country's macroeconomic environment and integration within the international economy (Potter, et al., 2013), SMEs are noted to be the most vulnerable, as they are considered insecure and volatile in the business environment. This also works against upcoming SMEs, which are still at a disadvantage in accessing reliable funding. Despite the attempts of corporations such as Banco Compartamos to finance small- and middle-level enterprises, a lack of audited accounts and proper management hinder young SMEs from accessing capital. It is high time that the relevant authorities move in and save SMEs by formulating new strategies on how they can access capital. This would enable the enterprises to effectively compete in the business environment.

\section{Invest in Training and Education of Young Investors with an Interest in SMEs}

To nurture a strong economy, the relevant authorities must invest heavily in education for young people about entrepreneurship and business. The country urgently needs to invest resources into raising its educational standards, achievement and attainment to prepare potential investors for investing in the economy. This can be attained by laying down policies and frameworks that will result in a large number of students completing their secondary and tertiary education. Levy (2007) argues that the main reason for Mexico's low productivity is the saturation of informal businesses, which is largely due to low levels of education among youth. Informal businesses are noted to be the number-one contributor to the country's plunging productivity (Bolio et al., 2014). With proper education, the masses will be well positioned to seek jobs and register their business complying with government's business regulations. This, too, will contribute to addressing unemployment and improve the living standards of the locals.

The present analysis has made clear that raising the productivity of small and medium enterprises (SMEs) in Mexico should be considered one of the country's main challenges. This sector is key to improving the overall productivity of the Mexican economy. While large companies are important, they will not likely raise the country's productivity by themselves. Sustainable economic progress for the country will leverage Mexico's current manufacturing competencies in existing value chains, and secure a competitive advantage in advanced manufacturing for the near future. Due to its strong connection with the primary and tertiary sectors, advanced manufacturing involves both the demand for raw materials, intermediate components, and many other services within the national economy (Sandoval et al., 2011). 


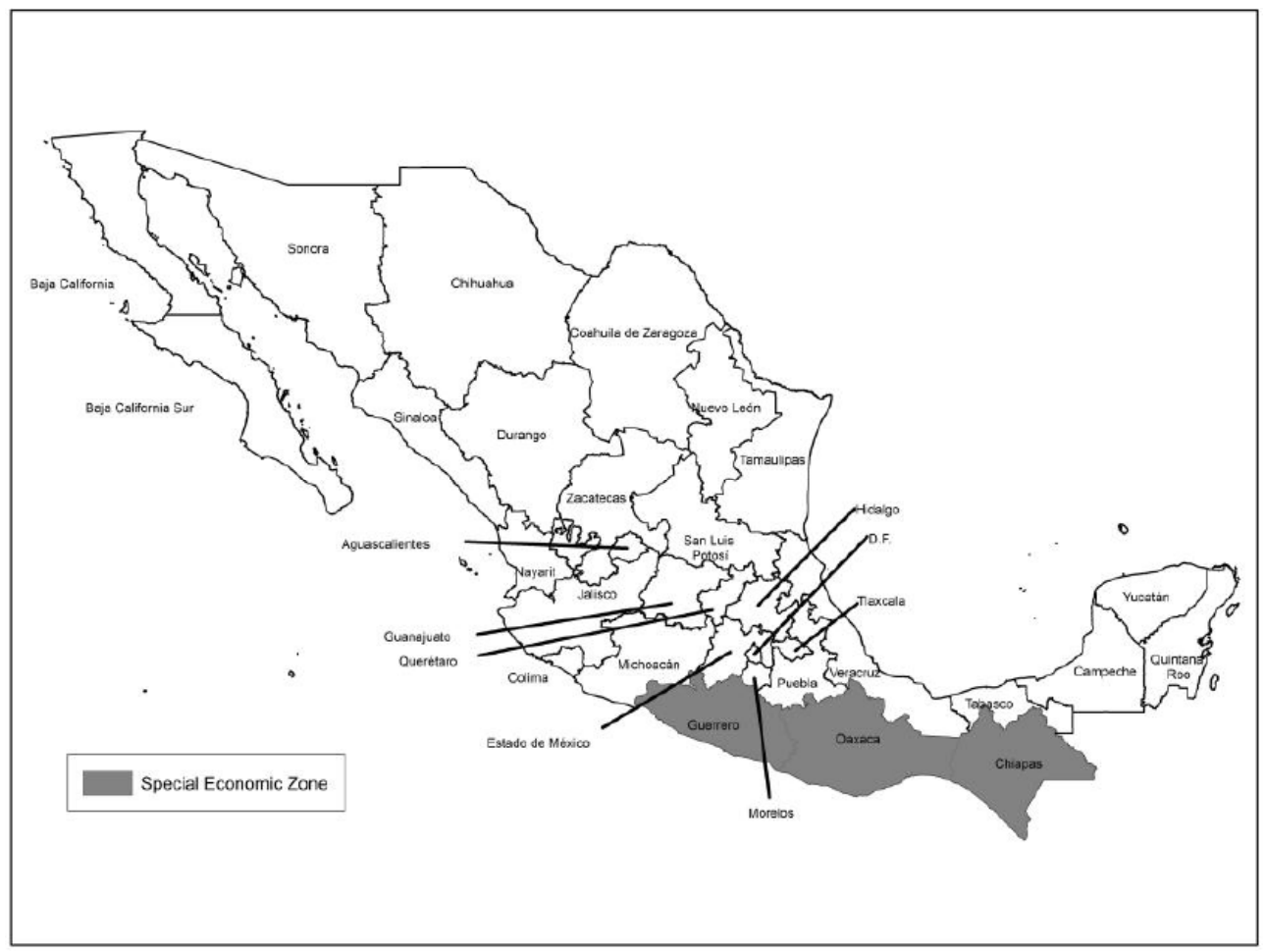

Appendix A: Mexican States and Special Economic Zone.

Source: Own elaboration based on SEDATU (2004).

Table A1: Correlation Matrix

\begin{tabular}{|c|c|c|c|c|c|c|c|c|c|}
\hline & $\begin{array}{l}\text { Prod. } \\
\text { Growth } \\
\text { 2004- } \\
2009\end{array}$ & $\begin{array}{l}\text { Productivity } \\
\text { at t0 }\end{array}$ & Patents & $\begin{array}{l}\text { Average } \\
\text { Schooling }\end{array}$ & $\begin{array}{c}\text { Population } \\
\text { density }\end{array}$ & Unemployment & $\begin{array}{c}\text { \%Rural } \\
\text { population }\end{array}$ & $\begin{array}{l}\text { Homicide } \\
\text { Rates }\end{array}$ & $\begin{array}{c}\text { Dummy } \\
\text { Variable } \\
\text { for the } \\
\text { Period } \\
2009- \\
2014\end{array}$ \\
\hline $\begin{array}{l}\text { Prod. Growth } \\
2004-2009\end{array}$ & 1 & & & & & & & & \\
\hline Patents & 0.127 & 0.505 & 1 & & & & & & \\
\hline $\begin{array}{l}\text { Average } \\
\text { Schooling }\end{array}$ & 0.225 & 0.606 & 0.413 & 1 & & & & & \\
\hline $\begin{array}{l}\text { Population } \\
\text { density }\end{array}$ & 0.130 & 0.241 & 0.588 & 0.175 & 1 & & & & \\
\hline $\begin{array}{l}\text { Homicide } \\
\text { Rates }\end{array}$ & -0.156 & -0.135 & -0.124 & 0.025 & -0.189 & -0.037 & -0.034 & 1 & \\
\hline $\begin{array}{l}\text { Dummy } \\
\text { Variable for } \\
\text { the Period } \\
2009-2014\end{array}$ & 0.512 & 0.152 & 0.153 & 0.311 & 0.028 & 0.336 & -0.039 & 0.166 & 1 \\
\hline
\end{tabular}




\section{Appendix B: Descriptive Statistics}

\begin{tabular}{|c|c|c|c|}
\hline & Mean & Std & Source \\
\hline \hline Productivity growth 2004-2014 & 0.027 & 0.031 & $\begin{array}{c}\text { Own calculation with data from } \\
\text { the Economic Census 2004, } \\
\text { 2009, and INEGI }\end{array}$ \\
\hline Patents per capita & 1.876 & 1.383 & INEGI \\
\hline Schooling Years & 0.905 & 0.051 & INEGI \\
\hline Unemployment & 0.395 & 0.214 & INEGI \\
\hline Population Dendity & 1.87 & 0.580 & INEGI \\
\hline \% Rural Population & 1.30 & 0.427 & INEGI \\
\hline Homicide Rates & 0.956 & 0.286 & INEGI \\
\hline
\end{tabular}

\section{REFERENCES}

Barro, R. and Sala-i-Martin, X. (2004). Economic Growth, Second Edition, MIT press.

Banaia N., Eberts, R., \& Fogarty, M. (1993) Universities and the startup of new companies: can we generalize from route 128 and Silicon Valley? Review of Economics and Statistics, 75(4), 761-766.

Bolio, E., Remes, J., Lajous, T. Manyika, J., Rosse, M., \& Ramirez, E. (2014). A tale of two Mexicos: Growth and prosperity in a two-speed economy. McKinsey Global Institute. http://www.mckinsey.com/insights/americas/a_tale_of_two_m exicos

Cravo, A., Gourlay., A., \& Becker, B. (2012). SMEs and Regional Economic Growth in Brazil. Small Bus Econ, 38, 217-230.

Dollar D., and Wolff E., (1988), "Covergence of Industry Labor Productivity among Advanced Economies, 1963-1982", The Review of Economics and Statistics, Vol. 70, No. 4, pp. 549558

Fazio G., \& Piacentino, D. (2010). A Spatial Multilevel Analysis of Italian SMEs Productivity. Spatial Economic Analysis, 5(3), 299-316.

Fong Reynoso, C., Alarcón Osuna, M. A., \& Ocampo Figueroa, L. E. (2014). Micro, Small and Medium-Sized Businesses in Jalisco: Their Evolution, and Strategic Challenges. Review of Business \& Finance Studies, 5(2), 27-43.

Hanson, G. (2010). Why Isn't Mexico Rich? NBERWorking Paper 16470. National Bureau of Economic Research.

Hulten, C. (2001). New Developments in Productivity Analysis. University of Chicago Press for National Bureau of Economic Research.

German-Soto, V., \& Gutierrez F. (2013). Assesing some determinants of regional patenting: an essay from Mexican States. Technology and Investment, 4, 1-9.

Griliches, Z. (1990). Patents Statistics as Economic Indicators: A Survey. NBER Working Paper No.3301. National Bureau of Economic Research.

INEGI (2011) Micro, pequeña, mediana y gran empresa: estratificación de los establecimientos: Censos Economicos 2009. Instituto Nacional de Estadistica y Geografia. Mexico: INEGI, c2011.

INEGI (2013) Analisis de la demografia de los resultados 2012. Instituto Nacional de Estadistica y Geografia. Mexico: INEGI, c2013.
Jo Bane, M., \& and Zenteno, R. (2009). Poverty and Poverty Alleviation Strategies in North America. In M. Jo Bane and R. Zenteno (Eds), The David Rockefeller Series on Latin American Studies, distributed by Harvard University Press, 2009.

Lee S., Florida, R., \& Zoltan, A. (2004). Creativity and Entrpreneurship: A regional Analysis of New Firm Formation. Regional Studies, 38(8), 879-891.

Lee I., Hong E., \& Sun, L. (2013). Regional knowledge production and entrepreneurial firm creation: spatial dynamic analysis. Journal of Business Research, 66, 2106-2115.

Levy, S. (2007). Can social programs reduce productivity and growth? A hypothesis for Mexico. IPC Working Paper Series Number 37, International Policy Center. University of Michigan.

Moretti, E. (2013) The New Geography of Jobs, Mariner Books, Houghton Mifflin Harcourt, Boston.

Munnell, A. (1990) Why Has Productivity Growth Declined? Productivity and Public Investment, New England Economic Review, January/Febrary, 1-22.

OECD (2010) SMEs, Entrepreneurship and Innovation, OECD Studies on SMEs and Entrepreneurship.

OECD (2013) Temas y Politicas Clave Sobre PYMES y Emprendimiento en Mexico, OECD Publishing.

Pan, M., Widner,B., \& Enomoto, E. (2012). Growth and crime in contiguous states of Mexico. Review of Urban and Regional Development Studies, 24, 51-64.

Potter, J., Marchese, M., Feldman, M., Kemeny, T., Lawton-Smith, H., \& Pike, T. (2013). The Local Dimension of SME and Entrepreneurship Issues and Policies in Mexico. OECD Local Economic and Employment Development (LEED) Working Papers, No. 2013/14. OECD Publishing, Paris.

Sandoval, R., Carreon, M., Ortiz, D., \& Moreno, J. (2011). Designated in Mexico: A Road-map for Design, Engineering, and Advanced Manufacturing, ProMexico.

SEDATU (2014). Programa Regional de Desarrollo del Sur-Sureste. Secretaria de Desarrollo Agrario, Territorial y Urbano. Direccion General de Desarrollo Regional.

Secretaria de Economia (2008). Diario Oficial, Miercoles 14 de mayo de 2008. http://www.fondopyme.gob.mx/2010/docs_pdfs/ progsectorialeconomia_DOF.pdf

Secretaria de Economia (2012). Consejo Nacional para la Competitividad de la Micro, Pequena y Mediana Empresa 
(CNCMIPYME). Secretaria de Economia, Administracion Publica Federal.

Sleuwaegen, L. \& Boiardi, P. (2014). Creativity and Regional Innovation: Evidence from EU regions. Research Policy, 43, 1508-1522.

Sprague, S. (2014), What can labor productivity tell us about the U.S. economy?, Bureau of labor statistics, May Vol.3, No.12.
Solow, R. (1956). A Contribution to the Theory of Economic Growth. Quaterly Journal of Economics, 70(1), 65-94.

UNCTAD (2010) Integrating Developing Countries' SMEs into Global Value Chains. United Nations, 2010.

Received on 08-03-2016

Accepted on 18-03-2016

Published on 06-05-2016

DOI: http://dx.doi.org/10.6000/1929-7092.2016.05.10

(C) 2016 Flores et al.; Licensee Lifescience Global.

This is an open access article licensed under the terms of the Creative Commons Attribution Non-Commercial License (http://creativecommons.org/licenses/by-nc/3.0/) which permits unrestricted, non-commercial use, distribution and reproduction in any medium, provided the work is properly cited. 